
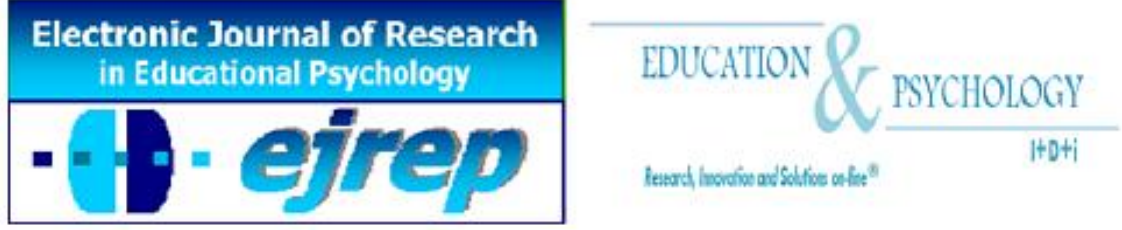

Ilustre Colegio Oficial

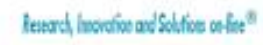

\title{
Navigation and Comprehension of Digital Expository Texts: Hypertext Structure, Previous Domain Knowledge, and Working Memory Capacity
}

\section{Debora I. Burin, Juan P. Barreyro, Gastón Saux, Natalia C. Irrazábal}

Universidad de Buenos Aires - CONICET, Buenos Aires

\section{Argentina}

Correspondence: Debora I. Burin. Universidad de Buenos Aires - CONICET. Instituto de Investigaciones, Facultad de Psicología, UBA. Lavalle 2353, (1052) Ciudad de Buenos Aires, Argentina. Phone: (54)(11) 49525481/49525490. E-mail: dburin@psi.uba.ar

(c) Education \& Psychology I+D+i and Ilustre Colegio Oficial de la Psicología de Andalucía Oriental (Spain) 


\begin{abstract}
Introduction. In contemporary information societies, reading digital text has become pervasive. One of the most distinctive features of digital texts is their internal connections via hyperlinks, resulting in non-linear hypertexts. Hypertext structure and previous knowledge affect navigation and comprehension of digital expository texts. From the Cognitive Load framework, working memory capacity would have a role in supporting decisions about navigation, and in situation model construction for comprehension. The present study assessed text structure, previous domain knowledge, and working memory capacity effects on comprehension and navigation of digital expository texts.

Method. Fifty-six participants completed a working memory capacity measure, read four digital texts and answered questions about them. Hyperext structure (hierarchical vs. network) and previous thematic knowledge (high vs. low) were manipulated in a within-subjects design. Navigation behavior was indexed taking into account total time spent on each text, total number of pages per text, number of returns to the initial page, and number of nonlinear links clicked.

Results. High previous knowledge, and high working memory capacity, led to better comprehension. Participants who read under network interfaces followed less structured navigation paths than those who read hierarchically organized interfaces. On the other hand, high previous knowledge texts led to more pages visited, more non-linear jumps in reading, and more returns to the overview in the Home page in the network condition. Also, total time spent on each text was longer for high working memory participants reading high previous knowledge texts.
\end{abstract}

Discussion. Overall, this pattern of results adds to the literature about the beneficial effects promoted by hierarchical interfaces and concept maps; and the disorientation effects network hypertexts have for low domain knowledge students. On the other hand, given good previous knowledge and high working memory, a more variable pattern of navigation would help readers engage in more active reading processes.

Keywords: digital text, navigation, comprehension, working memory

Reception: 04.16.15 Initial acceptance: 05.25.15 Final acceptance: 06.11.15 


\section{Navegación y comprensión de textos digitales: estructuras de hipertexto, conocimientos previos del dominio y capacidad de memoria de trabajo Resumen}

Introducción. La lectura de textos digitales es cada vez más extendida en la sociedad de la información contemporánea. Uno de los rasgos más salientes de los textos digitales es su interconexión mediante enlaces, resultando en hipertextos no lineales. Entre los principales factores que afectan a la comprensión de textos expositivos digitales se encuentran la estructura del hipertexto y el conocimiento previo específico de dominio. Desde la teoría de la Carga Cognitiva, la capacidad de la memoria de trabajo debería también jugar un papel en las decisiones sobre la navegación, así como en la construcción del modelo de situación para la comprensión. El presente experimento analizó los efectos de la estructura hipertextual, el conocimiento previo, y la capacidad de la memoria de trabajo, en la navegación y comprensión de textos expositivos digitales.

Método. Cincuenta y seis participantes completaron un test de memoria de trabajo, y leyeron cuatro textos digitales para luego contestar preguntas sobre los mismos. En un diseño intrasujeto se manipularon la estructura del hipertexto (jerárquica vs. en red) y el conocimiento específico de dominio (alto vs. bajo). La navegación se indexó teniendo en cuenta el tiempo total empleado en cada texto, el número total de páginas visitadas por texto, el número de vueltas a la página de inicio, y el número de enlaces no lineales visitados.

Resultados. Se hallaron mejores resultados en comprensión para los textos de alto conocimiento previo y para los participantes con alta capacidad de memoria de trabajo. La interfase en red condujo a una navegación menos lineal respecto de la estructura jerárquica. Por otro lado, en la estructura en red, los textos de alto conocimiento previo llevaron a visitar más páginas, a más enlaces no lineales durante la lectura, y a una mayor cantidad de retornos a la página de inicio. Asimismo, los participantes con alta memoria de trabajo que leían textos de alto conocimiento previo emplearon mayor tiempo en total.

Discusión. En conjunto, este patrón de resultados se suma a la literatura acerca de los beneficios que provee una interfase jerárquica, y a los efectos de desorientación que tienen los hipertextos no estructurados, cuando el conocimiento previo es bajo. Por otro lado, cuando el conocimiento previo es alto y los participantes poseen alta capacidad de memoria de trabajo, un patrón de navegación más variable ayudaría a promover una construcción más activa en la comprensión lectora.

Palabras Clave: texto digital; navegación, comprensión lectora; memoria de trabajo. 


\section{Introduction}

Understanding text is a complex task that involves basic processing at phonological, lexical-semantic and syntactic levels, as well as inferential processes to connect both the various parts of the text together, and to the subject's previous knowledge in order to build a coherent situation model of the events depicted by print (Graesser \& Britton, 1996; Graesser, León, \& Otero, 2002). Expository texts such as textbooks, scientific articles, magazine and newspaper reports for the general public, are written to explain and describe content information that has a foundation in purported facts (Graesser, León, \& Otero, 2002). Crucial factors for comprehension are previous domain knowledge, discourse and vocabulary knowledge, text coherence and organization, and individual differences in reading skills, working memory, and motivation (De Magistris, Richards, \& Canet Juric, 2014; Graesser, León, \& Otero, 2002).

In contemporary information societies, reading digital text has become so common that it has been incorporated in transnational assessments of basic school competencies (OECD, 2009). Even though reading and understanding text share core processing requirements across media, digital texts have additional specific features needing processing. One of the most distinctive features of digital texts is their internal connections via hyperlinks, resulting in non-linear hypertexts instead of the traditional paper versions. This requires readers to select links and evaluate if and how the information shown fits the situation model, and to incorporate relevant and discard irrelevant information (DeStefano \& LeFevre, 2007; Salmerón, Cañas, Kintsch \& Fajardo, 2005; Shapiro \& Niederhausen, 2004). Factors affecting understanding expository hypertexts can arise from hypertext structure and interface design, users' individual differences, and contextual aspects (Dillon \& Jobst, 2005; Shapiro \& Niederhausen, 2004). Among these, two of the better known factors affecting navigation decisions and comprehension outcomes in expository hypertexts are its structure and interface design, and the reader's prior domain knowledge.

Regarding structure, studies have usually compared linear or hierarchical interface structures with unstructured or network ones, accompanied by graphical organizers or conceptual maps of the content. In comprehension tasks, many studies have shown general differences in favor of hierarchical structures, providing an overall organized overview summariz- 
ing content (Amadieu, Tricot, \& Marine, 2009, Amadieu, Van Gog, Paas, Tricot, \& Mariné, 2010; Britt, Rouet, \& Perfetti, 1996; Klois, Segers \& Verhoeven, 2013; Müller-Kalthoff \& Möller, 2004; Potelle \& Rouet, 2003; Salmerón, Baccino, Cañas, Madrid, \& Fajardo, 2009, Salmerón, Cañas, Kintsch \& Fajardo, 2005; see also the review by Amadieu \& Salmerón, 2014), whereas others did not (de Jong \& van der Hulst, 2002; Dee-Lucas, 1996; Hofman \& van Oostendorp, 1999; Lee \& Tedder, 2003; see also Amadieu \& Salmerón, 2014). In contrast, network presentations, without any hierarchy, path, or metaphor to organize the content, seem to lead to cognitive overload and disorientation, resulting in inefficient navigation and problems in comprehension.

Structure effects have been shown to interact with readers' prior domain knowledge, which may provide a semantic representation helping to organize the information presented by the hypertext. Research has repeatedly shown that when participants' previous knowledge of the domain studied was low, comprehension outcomes were better with a structured hierarchical interface; but in high previous knowledge this advantage was absent (Amadieu et al., 2009, 2010; Calisir \& Gurel, 2003; de Jong \& van der Hulst, 2002; Hofman \& van Oostendorp, 1999; Potelle \& Rouet, 2003; Salmerón et al., 2005, 2006; Salmerón, Baccino, Cañas, Madrid, \& Fajardo, 2009). In the case of low prior knowledge readers, a network structured interface, without any hierarchy or graphical depiction of semantic organization, seems to lead to cognitive overload and disorientation, resulting in inefficient navigation and problems in comprehension; while a structured presentation would help building a coherent situation model. In contrast, readers with high previous knowledge would employ their acquired information to make decisions about what to read next, and how different contents are related to each other, so that a disorganized presentation would not affect performance. Moreover, some studies found a reversal effect: deep comprehension in high previous knowledge was best supported by ill-structured, more challenging interfaces (Salmerón et al., 2005, 2006; Shapiro \& Niederhausen, 2004).

Studies of navigation in comprehension tasks with objective measures such as time per node, number of nodes, reading sequences, obtained with log analyses and eye-tracking methods, have supported the navigation assumptions related to prior knowledge effects. Low previous knowledge participants, when given a hierarchical or more structured overview, tended to spend more time reading it, and had better performance than with network interfaces (Amadieu et al., 2009, 2010; Klois et al., 2013). Also, better comprehension was achieved by 
low previous knowledge readers who chose more coherent paths, or who spent more time on a structured overview (Salmerón et al., 2006, 2009). High previous knowledge participants showed more variable navigation patterns in both types of interfaces, suggesting an active navigation not constrained by the system (Amadieu et al., 2010); in other studies, for high previous knowledge readers a better deep comprehension was achieved by those who followed less coherent navigation paths (Salmerón et al., 2006, 2009).

Aside from structure and domain specific knowledge, other aspects of the task and individual characteristics may regulate digital text navigation and comprehension. Cognitive Load theory was proposed as a comprehensive framework to account for efficiency of learning devices, and has promoted research in multimedia digital educational tools (DeStefano \& LeFevre, 2007; Paas, Renkl, \& Sweller, 2004; Sweller, 2004). Cognitive load is a construct which encompasses at least two dimensions, mental load and mental effort (de Jong, 2009; DeStefano \& LeFevre, 2007; Paas et al., 2004). Mental load is imposed by task design (e.g., task structure, content, evaluation), and mental effort refers to the reader's mental characteristics when attempting the task, and their interaction with task demands. One of the central tenets of the cognitive load framework is that mental load taxes working memory resources (DeStefano \& LeFevre, 2007; Paas et al., 2004; Sweller, 2004). Working memory refers to the cognitive structures and processes supporting online effortful processing, and consists of partially independent components to deal with auditory-verbal and visuo-spatial information, and a central executive responsible for attentional focusing, shifting, updating and retrieving from long-term memory (Baddeley, 2003; Miyake \& Shah, 1999). Working memory is limited in capacity and resources, so there is a limited amount of information that can be activated and processed at a given moment.

Cognitive load has been assessed as a function of learning design (mostly, varying the modality and requirements of the presentation) and subjectively, with different versions of self-reported measures addressing perceived mental effort (de Jong, 2009; Moreno, 2009). Some studies directly measured participants' working memory capacities (Jong, 2009; Moreno, 2009), observing interactions between this capacity and instructional manipulation effects, which appeared to hold only for low working memory capacity learners. For example, Lusk and colleagues (Lusk, Evans, Jeffrey, Palmer, Wikstrom, \& Doolittle, 2009) studied the effects of segmenting multimedia presentations, allowing learners to pace their own training instead of watching a video. Working memory capacity was assessed with the Operation Span 
test. They found a positive effect of segmentation in recall and elaborative inferences, and an interaction, in the sense that low working memory capacity participants were especially affected without segmentation.

As reviewed above, hypertext structure and previous knowledge have main and interactive effects when understanding expository digital texts. From the Cognitive Load perspective, these can be seen as sources of mental load (DeStefano \& LeFevre, 2007). This framework also predicts that working memory capacity would have moderating effects of structure and previous knowledge, given its role in supporting decisions about navigation, as well as in situation model construction (DeStefano \& LeFevre, 2007). In this direction, Juvina and van Oostendorp (2008) analyzed performance on six problem solving tasks based on Internet information search, with spatial ability (a test of mental rotation), working memory (tested with Reading Span), episodic memory (image recall and recognition), and domain knowledge as predictors, in an experiment with thirty participants. They found that spatial ability and domain knowledge, but not working memory, contributed to efficient performance and revisits to previous pages, number of pages visited, and path adequacy. In a similar vein, Gwizdka (2009) assessed the effects of individual differences in working memory capacity (operation span) and spatial ability (mental rotation) on different types of web navigation and search performance (such as search formulation, search results inspection, relevance judgment), in a sample of forty eight college students. Tasks were designed to differ in terms of their difficulty and structure. Search task navigaton and outcomes were affected by the objective task difficulty and interface structure. As for individual differences in working memory, participants with higher working memory tended to spend more time, visit more pages, and perform more cognitive actions (such as bookmarking). Working memory capacity did not have a significant effect on search efficiency (such as linearity departures or revisits) nor on search outcomes. However, in both cases tasks involved search and not learning.

Lee and Tedder (2003) found that low working memory participants had better content recall with a linear structure than with a network one; however, they introduced a confound by testing recall of text as an outcome variable. Naumann and colleagues (Naumann, Richter, Christmann, \& Groeben, 2008) studied how working memory and reading skills moderated effects of strategy training when learning from a scientific hypertext (writing a summary), and whether the quality of navigational behavior mediates these effects. The cognitive load hypothesis predicted that learning and employing new strategies, still not automatized, would 
tax working memory. As expected, the learning outcomes of high working memory capacity were improved by both a cognitive and a metacognitive strategy training, but for participants with low working memory capacity both types of training negatively affected performance. These effects were also apparent in navigational behavior, as indexed by the number of visits to task relevant content pages. They did not find main effects of working memory capacity in comprehension in the control (non-trained) group.

In summary, the cognitive load framework assumes that working memory capacity would interact with structural aspects of the digital material to be learned, and with previous knowledge of the content, when understanding digital expository texts. However, previous research has focused on navigation and search, or interactions with treatment, rather than its effects on comprehension outcomes, and is not conclusive.

\section{The present study}

In the present study we systematically varied the digital text structure (hierarchical vs. network), and previous thematic knowledge (high vs. low), and we examined the effects of these factors on comprehension and navigation, when reading digital expository texts for understanding in order to answer questions. As in Klois et al. (2013), structure and previous knowledge were manipulated in a within-subjects design: each participant read four texts (two in each structure, two in each previous knowledge level). Also in keeping with previous research (Amadieu et al., 2009, 2010; Gwizdka, 2009; Juvina and van Oostendorp, 2008; Klois et al., 2013; Salmerón et al., 2006, 2009), navigation behavior was indexed taking into account total time spent on each text, total number of pages per text, number of returns to the initial page, and number of nonlinear links clicked. In addition, each participant completed a working memory capacity measure. Thus, the experiment sought to examine effects of structure, previous knowledge, and working memory capacity, in navigation and comprehension of digital texts.

\section{Method}

\section{Participants}

Fifty-six participants (age $\mathrm{M}=22.1, \mathrm{SD}=4.8$ ), attending an introductory cognitive psychology course, took part of the study as volunteers, in exchange for partial credit. When 
comparing low and high working memory groups, after eliminating those with median working memory capacity the samples comprised 44 participants.

\section{Instruments}

We employed four expository texts, two about cognitive psychology (Memory, Language) and two about natural sciences (Astronomy, Particle Physics), composed of 712-719 words, and the same expository structure: (1) General concept; (2) Subordinate concept A; (3) Concept A -Details; (4) Subordinate concept B; (5) Concept B - Details; (6) Problem or comparison relating $A$ to $B$; (7) Conclusion. Texts were pre-tested in paper format, to correct wording, coherence, and content. Each text was implemented in seven different nodes (pages), and organized under two structures, Hierarchical and Network, pre-tested for design, content and navigation usability in two online studies. So then, for each text, there were two versions, hierarchical and network; respective examples can be seen in Figs. 1 and 2.

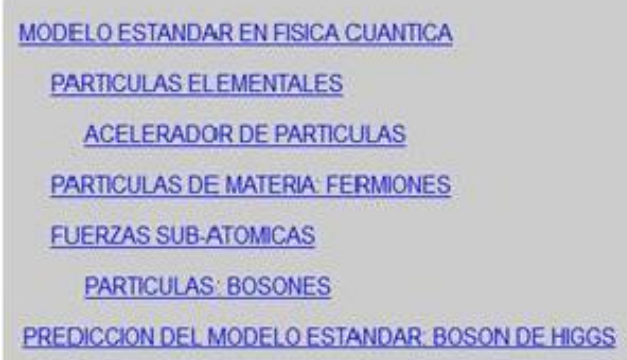

Al finalizar el siglo XIX se sabía que toda materia estaba formada por átomos. Con el desarrollo de la física nuclear en el siglo XX se comprobó que el átomo puede subdividirse en particulas más pequeñas. La teoría aceptada hoy es que el átomo se compone de un núcleo de carga positiva formado por protones y neutrones, en conjunto conocidos como nucleón, alrededor del cual se encuentra una nube de electrones de carga negativa. Sin embargo, a partir de los años 1970 quedó claro que los protones y neutrones son partículas compuestas de otras particulas más simples, llamadas particulas elementales. Son los constituyentes elementales de la materia, los abjetos más simples que se pueden concebir. 


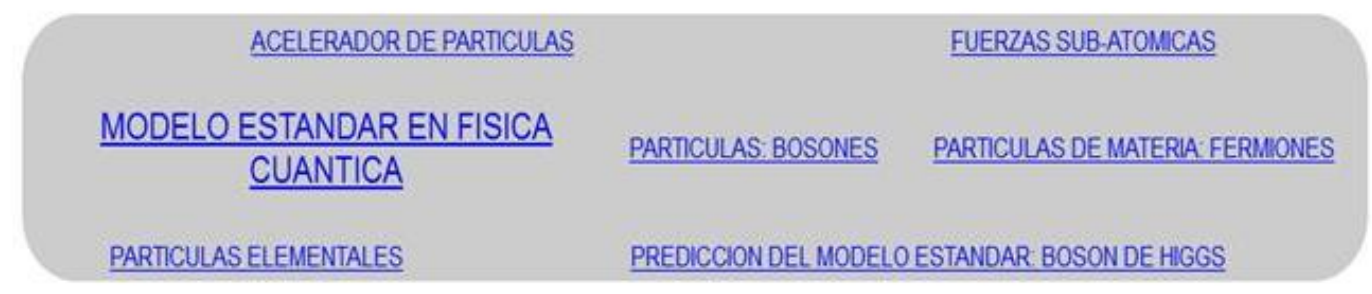

TERMINAR

\begin{abstract}
Al finalizar el siglo XIX se sabia que toda materia estaba formada por átomos. Con el desarrollo de la física nuclear en el siglo XX se comprobó que el átomo puede subdividirse en partículas más pequeñas. La teoría aceptada hoy es que el átomo se compone de un núcleo de carga positiva formado por protones y neutrones, en conjunto conocidos como nucleón, alrededor del cual se encuentra una nube de electrones de carga negativa. Sin embargo, a partir de los años 1970 quedó claro que los protones y neutrones son partículas compuestas de otras partículas más simples, llamadas partículas elementales. Son los constituyentes elementales de la materia, los objetos más simples que se pueden concebir.
\end{abstract}

Figure 2. Example of Home page and content page for Network structure

Hierarchical texts presented an overview first page (Home) showing the titles for each content node (page) in a tree-like structure. The order of the nodes, though not the hierarchical organization, was repeated in a side-bar in each of the content pages. Navigation included links in the side-bar, and a link to Home. Network texts showed a Home page with an overview with the same titles in a "cloud" fashion, in alphabetical order; and in each content page, there were two embedded linked words which led to another page of the hypertext. Relative to a linear order, one of the links led to the next page, and the other to the following, that is, two pages ahead. Navigation included these embedded links, and a link to Home.

Each individual session was registered with WebSTAT software (WebSTAT, n/d). Based on these measures and indexes employed by previous researchers (Amadieu et al., 
2009, 2010; Gwizdka, 2009; Juvina and van Oostendorp, 2008; Klois et al., 2013; Salmerón et al., 2006, 2009) we computed the following navigation variables per hypertext: Total time (sum of the time logged on each individual page since the hypertext opened until the participant clicked on a "Finish" button); Number of pages visited; Number of clicks on the Home link (which contained the overview); and Departure from Linearity (Klois et al., 2013), indexed as clicks to a page more than one node ahead or behind from textual linearity excluding Home (each "jump" counts as 1 , so increases in this variable represent less linearity or coherence).

Comprehension was assessed with a sentence verification task (True / False), with eight items per text tapping literal information. Working Memory (WM) capacity was assessed with the Letter-Number Sequencing subtest - WAIS III (Wechsler, 2003), which was administered and scored according to the Manual. Participants also completed an ad-hoc structured questionnaire about Internet experience and knowledge.

\section{Procedure}

In individual sessions, lasting thirty to forty minutes approximately, each participant completed all tasks. First, they completed a questionnaire asking for demographical variables and Internet experience, followed by the Letter-Number Sequencing test, and the digital texts task. For this task, they were instructed to read at their own pace, to understand the texts, because they were going to answer True / False questions about them. They were specifically asked to read attentively and take notes, and were provided with sheets of paper to do so; they could consult their notes when answering the questions about the text. Thus, the goal was to probe comprehension and not memory for text.

Each participant read four hypertexts, one for each level of previous domain knowledge (low, high) and structure (hierarchical, network), in counterbalanced order. Comprehension tasks (sentence verification) were completed after each text; thus, participants read one text, performed its comprehension task, and continued with the following text. A debriefing explanation at the end of the session was provided.

\section{Data Analysis}


Several mixed analyses of variance with hypertext structure (hierarchical and network) and previous knowledge (high and low) as within-subjects factors, and working memory (high and low) as a between-subjects factor, were carried out. For all analyses, participants were assigned to a High or Low Working Memory (WM) capacity group according to their performance relative to the median on the working memory test; subjects whose performance was identical to the median were discarded. Therefore, the High WM group comprises 18 and the Low WM group, 26 participants. Dependant variables were: the number of correct responses on the sentence verification task, as a measure of comprehension outcome, and total time; number of pages visited; number of clicks on the Home link; and departure from linearity, as measures of navigation.

\section{Results}

Comprehension accuracy. A mixed analysis of variance with text structure (hierarchical and network) and previous knowledge (high and low) as a within variables and working memory (high and low) as a between variables was carried out. Dependant variable was the number of correct responses on the sentence verification task. Table 1 shows comprehension accuracy as a function of type of structure, previous knowledge and working memory. The analysis revealed a main effect of previous knowledge on comprehension accuracy $F$ (1, $42)=8.39, M S E=0.96, p=.01, \eta^{2}=.17$, a marginal effect of working memory $F(1,42)=$ 3.91, $M S E=1.61, p=.06, \eta^{2}=.08$, and non-significant effects of structure $F(1,42)=0.86$, $M S E=0.93, p=.36, \eta^{2}=.02$. Interactions between variables were non-significant. According to these results, high previous knowledge readers had better comprehension $(M=6.53, S E=$ $0.11)$ than low previous knowledge readers $(M=6.09, S E=0.13)$, and also high working memory readers $(M=6.50, S E=0.15)$ compared with low working memory readers $(M=$ 6.12, $S E=0.12)$. 
Table 1. Comprehension Accuracy for Hypertext Structure (Hierarchical and Network), Previous Knowledge and Working Memory.

\begin{tabular}{rlcccc}
\hline & \multicolumn{2}{c}{ High WM } & \multicolumn{2}{c}{ Low WM } \\
\cline { 3 - 6 } & & $M$ & $S D$ & $M$ & $S D$ \\
\hline Hierarchical High PK & 6.61 & 0.92 & 6.58 & 1.03 \\
& Low PK & 6.28 & 1.23 & 6.04 & 1.08 \\
Network & High PK & 6.72 & 1.07 & 6.19 & 1.06 \\
& Low PK & 6.39 & 1.24 & 5.65 & 0.80 \\
\hline \multicolumn{2}{c}{ PK = Previous Knowledge, WM = Working Memory } & &
\end{tabular}

$\mathrm{PK}=$ Previous Knowledge, $\mathrm{WM}=$ Working Memory

Total Time spent on task. A similar mixed ANOVA was conducted to study the effect of hypertext structure, previous knowledge and working memory on navigation time in each hypertext. Dependent variable was total time spent per hypertext. Table 2 shows total time as a function of those variables. Neither structure $(F(1,42)=0.01, \operatorname{MSE}=101458.09, p=.92$, $\left.\eta^{2}=.00\right)$ nor previous knowledge $\left(F(1,42)=0.26, M S E=56135.77, p=.62, \eta^{2}=.01\right)$ or working memory $\left(F(1,42)=2.67, M S E=226083.20, p=.11, \eta^{2}=.06\right)$, had significant effects. But a significant interaction between previous knowledge and working memory was found $\left(F(1,42)=6.88, M S E=56135.77, p=.01, \eta^{2}=.14\right)$. Post hoc tests show that for high previous knowledge text, high working memory readers spent significantly $(p<.05)$ more time $(M=900.86, S E=63.07)$ than low working memory readers $(M=686.42, S E=52.48)$. This difference was not observed in the low previous knowledge text condition, between high $(M=787.22, S E=62.14)$ and low working memory readers $(M=763.35, S E=51.71)$.

Table 2. Total Time as a function of Hypertext Structure (Hierarchical and Network), Previous Knowledge and Working Memory.

\begin{tabular}{llcccc}
\hline & \multicolumn{2}{c}{ High WM } & \multicolumn{2}{c}{ Low WM } \\
\cline { 3 - 6 } & & $M$ & $S D$ & $M$ & $S D$ \\
\hline Hierarchical & High PK & 872.06 & 466.01 & 693.62 & 263.22 \\
& Low PK & 801.50 & 347.50 & 781.19 & 365.91 \\
\multirow{4}{*}{ Network } & High PK & 929.67 & 354.71 & 679.23 & 270.87 \\
& Low PK & 772.94 & 318.78 & 745.50 & 286.89 \\
\hline
\end{tabular}

$\mathrm{PK}=$ Previous Knowledge, $\mathrm{WM}=$ Working Memory 
Total number of pages visited. A similar mixed ANOVA was conducted to study the effect of hypertext structure, previous knowledge and working memory on the number of pages visited for each hypertext. Dependent variable was total number of pages visited per hypertext. Table 3 shows number of pages as a function of structure, knowledge and working memory. The analysis shows main effects of hypertext structure $(F(1,42)=39.92, M S E=$ $\left.47.85, p<.001, \eta^{2}=.49\right)$, and previous knowledge $(F(1,42)=4.78, M S E=143.67, p=.03$, $\left.\eta^{2}=.10\right)$, but not of working memory $\left(F(1,42)=0.08, M S E=76.75, p=.77, \eta^{2}=.00\right)$. Interaction effects between the variables were not significant. According to these results, readers who read hierarchical hypertexts opened fewer pages $(M=13.51, S E=0.61)$ compared with readers that read network hypertexts $(M=20.22, S E=1.05)$, and high previous knowledge readers open more pages $(M=17.92, S E=0.88)$ than low previous knowledge readers $(M=15.81, S E=0.77)$.

Table 3. Number of Pages as a function of Hypertext Structure (Hierarchical and Network), Previous Knowledge and Working Memory.

\begin{tabular}{llcccc}
\hline & \multicolumn{2}{c}{ High WM } & \multicolumn{2}{c}{ Low WM } \\
\cline { 3 - 6 } & & $M$ & $S D$ & $M$ & $S D$ \\
\hline Hierarchical & High PK & 14.89 & 5.73 & 13.04 & 6.00 \\
& Low PK & 12.17 & 3.11 & 13.96 & 6.13 \\
\multirow{3}{*}{ Network } & High PK & 23.17 & 8.16 & 20.58 & 9.53 \\
& Low PK & 18.00 & 5.26 & 19.12 & 8.24 \\
\hline
\end{tabular}

PK = Previous Knowledge, WM = Working Memory

Returns to Home. A similar mixed ANOVA was carried out, with the number of clicks on the Home link (which contained the overview) as the dependent variable (see Table 4). Structure had a significant effect $\left(F(1,42)=52.81, M S E=11.23, p<.001, \eta^{2}=.56\right)$, and the interaction between structure and previous knowledge was also significant $(F(1,42)=7.12$, $\left.M S E=2.63, p=.01, \eta^{2}=.15\right)$. Previous knowledge $\left(F(1,42)=3.26, M S E=5.50, p=.08, \eta^{2}\right.$ $=.07)$ and working memory $\left(F(1,42)=0.07, M S E=15.11, p=.80, \eta^{2}=.00\right)$ did not have significant effects. Participants who read under a network structure returned more to see the overview $(M=6.82, S E=0.50)$ compared with readers of hierarchical texts $(M=3.08, S E=$ 0.24), and post-hoc analyses of the interaction reveal that in the hierarchical condition high and low previous knowledge readers did not differ (high PK $M=3.07, S E=0.29$, and low PK $M=3.09, S E=0.30$ ) whereas in the network condition high previous knowledge readers re- 
turned more to Home $(M=7.47, S E=0.58)$ than low previous knowledge readers $(M=6.16$, $S E=0.54)$.

Table 4. Returns to Home as a function of Hypertext Structure (Hierarchical and Network), Previous Knowledge and Working Memory.

\begin{tabular}{llcccc}
\hline & \multicolumn{2}{c}{ High WM } & \multicolumn{2}{c}{ Low WM } \\
\cline { 3 - 6 } & & $M$ & $S D$ & $M$ & $S D$ \\
\hline Hierarchical & High PK & 3.15 & 2.22 & 3.00 & 1.28 \\
& Low PK & 3.46 & 2.21 & 2.72 & 1.53 \\
\multirow{3}{*}{ Network } & High PK & 6.62 & 3.89 & 8.33 & 3.69 \\
& Low PK & 6.27 & 4.03 & 6.06 & 2.64 \\
\hline
\end{tabular}

$\mathrm{PK}=$ Previous Knowledge, $\mathrm{WM}=$ Working Memory

Number of non-linear clicks. The mixed ANOVA performed to study the effect of structure, previous knowledge and working memory on the index of departure from linearity, shows a main effect of structure $\left(F(1,42)=70.80, M S E=6.36, p<.001, \eta^{2}=.63\right)$, and a main effect of knowledge $\left(F(1,42)=12.03, M S E=2.71, p=.001, \eta^{2}=.22\right)$. Working memory did not have a significant effect $\left(F(1,42)=0.41, M S E=7.22, p=.53, \eta^{2}=.07\right)$. Table 5 shows the index of departure from linearity as a function of type of structure, previous knowledge and working memory. According to these results, texts with a network structure conduce to more departure from linearity $(M=3.59, S E=0.39)$ than hierarchical texts $(M$ $=0.34, S E=0.09)$, and high previous knowledge readers read more non-linearly $(M=2.40$, $S E=0.27)$ than low previous knowledge readers $(M=1.53, S E=0.21)$.

Table 5. Departure from Linearity as a function of Hypertext Structure (Hierarchical and Network), Previous Knowledge and Working Memory.

\begin{tabular}{llcccc}
\hline & \multicolumn{2}{c}{ High WM } & \multicolumn{2}{c}{ Low WM } \\
\cline { 3 - 6 } & $M$ & $S D$ & $M$ & $S D$ \\
\hline Hierarchical High PK & 0.38 & 0.90 & 0.61 & 0.98 \\
& Low PK & 0.19 & 0.49 & 0.17 & 0.38 \\
\multirow{4}{*}{ Network } & High PK & 4.62 & 3.73 & 4.00 & 3.05 \\
& Low PK & 3.19 & 2.23 & 2.56 & 2.92 \\
\hline \multicolumn{3}{c}{ PK = Previous Knowledge, WM = Working Memory }
\end{tabular}




\section{Discussion}

The present study examined the effects of hypertext structure and previous domain knowledge, as sources of mental load, and participants' working memory capacity, as posited by the cognitive load framework, in expository digital text navigation and comprehension.

Previous knowledge had a significant effect on comprehension, so that high previous knowledge texts had more correct answers to questions; this result was expected and replicated previous findings in traditional expository text (Graesser et al., 2002) and hypertext comprehension (Amadieu \& Salmeron, 2014; Dillon \& Jobst, 2005). Together with the fact that comprehension was better, high previous knowledge texts led to more pages visited, and more non-linear jumps in reading. Given that those navigation measures indicate decisions about following links, and integration processes in reading, in terms of the cognitive load framework they would mean that participants engaged in more cognitive load when processing high previous knowledge texts. Therefore, high previous knowledge would act as a buffer of mental load (DeStefano \& LeFevre, 2007). Moreover, the interaction between previous knowledge and hypertext structure on returns to Home, which presented an overview of all the links, reinforces this interpretation: although there were no differences in a hierarchical navigation, in the network condition there were more returns to Home for high previous knowledge texts. Thus, previous knowledge served as a source of coherence and organization, providing relief for mental load, when the interface was not structured.

This pattern of results is in line with findings by Amadieu et al. $(2009,2010)$ and Salmerón et al. $(2006,2009)$ in the sense that for high previous knowledge better comprehension was achieved by those who followed less coherent navigation paths. It should be noted that in our case, participants could take notes while reading, and consult them when answering questions; it might have facilitated a strategy to build complete situation models instead of trying to memorize facts, thus more pages visited and more jumps when the general facts were already known.

In line with the mental load hypothesis and previous literature, hypertext structure affected navigation. It did not have a significant effect on total time, but that time was spent differently for each structure. Participants who read under network interfaces visited more pages, returned more to Home, and followed less linear paths, than those who read hierarchically organized interfaces. This pattern suggests that their reading time was spent in a lesser 


\section{Navigation and Comprehension of Digital Expository Texts: \\ Hypertext Structure, Previous Domain Knowledge, and Working Memory Capacity}

extent in content pages, and more in broken paths and decisions about links (Amadieu et al., 2009, 2010; Klois et al., 2013; Potelle \& Rouet, 2003; Salmeron et al., 2006). Thus, a network presentation would increase mental load, in terms of the cognitive load framework (DeStefano \& LeFevre, 2007).

Whether a non-structured interface led to comprehension faults depended on other sources of load and performance factors. This interpretation would be supported by the interaction between structure and previous knowledge on returns to Home previously discussed: under a hierarchical structure, high and low previous knowledge texts did not differ, whereas in the network condition high previous knowledge readers, who had better comprehension, returned more than low previous knowledge readers, who could be ignoring parts of the material (therefore less comprehension accuracy).

One of the main objectives in this study was working memory capacity's role when navigating expository digital text for comprehension, posited by the cognitive load framework (DeStefano \& LeFevre, 2007; Paas et al., 2004; Sweller, 2004). Results gave only a partial support for this assumption. On one hand, working memory capacity had a marginally significant effect on comprehension questions. This replicates classic text comprehension effects (Graesser et al., 2002) and continues work by Lee and Tedder (2003) in hypertext comprehension, but working memory involvement in comprehension in our study was not confounded by recall of facts; this emphasizes working memory's role in constructing and integrating the mental model of the content. On the other hand, working memory did not have a main effect in navigation indexes, and only showed moderating effects of previous knowledge and structure in total time spent on texts, which was longer for high working memory participants reading high previous knowledge texts. This result is comparable to that obtained by Gwizdka (2009) in more complex search tasks. Given that high working memory participants and high previous knowledge texts had better results on comprehension, the result could also suggest that when mental load is not overtaxed, readers engage in more active and thorough processing, constructing a better model of the content.

The lack of a main effect of working memory capacity on other indexes of navigation was also observed in related studies, such as in search tasks (Juvina \& van Oostendorp, 2008), and the untrained group in Naumann et al.'s (2008) study on science comprehension. Combined with the previous observation that working memory effects are seen in complex tasks and /or extreme ability by task interactions; it could be that the reading and comprehension 
task administered here, to psychology college students, did not pose a significant stretch to their working memory capacity.

Overall, this pattern of results add to the literature about the beneficial effects, and the constraints in navigation, promoted by hierarchical interfaces and concept maps; and the disorientation effects network hypertexts have for low domain knowledge students (Amadieu \& Salmeron, 2014). On the other hand, given a good previous knowledge and high working memory, when mental load is not overtaxed, unstructured navigation or a more variable pattern of navigation would help readers engage in more active constructive processes. These results could provide guidelines for writers and designers of academic expository texts.

Known cognitive load factors such as previous knowledge and complexity of the task (given by hypertext structure) showed expected effects in comprehension and navigation, as did working memory capacity in comprehension. Moderating effects of working memory capacity on other load factors showed only in total time spent in navigation, suggesting that they appear in more complex and /or extreme ability by task interactions. Future studies could examine more difficult tasks and/or less skilled samples.

\section{Acknowledgements}

Financial support for this project was given by research grants provided by Consejo Nacional de Investigaciones Cientificas y Tecnicas de Argentina (PIP 11220090100036), and Secretaría de Ciencia y Técnica, Universidad de Buenos Aires (UBACYT 20020110100033CO). We thank Mg. Ezequiel Kahan for his help in site construction and testing.

\section{References}

Amadieu, F., \& Salmerón, L. (2014). Concept maps for comprehension and navigation of hypertexts. In R. Hanewald \& D. Ifenthaler (Eds). Digital Knowledge Maps in Education (pp. 41-59). New York: Springer. doi:10.1007/978-1-4614-3178-7_3

Amadieu, F., Tricot, A., \& Mariné, C. (2010). Interaction between prior knowledge and concept-map structure on hypertext comprehension, coherence of reading orders and disorientation. Interacting with Computers, 22, 88-97. doi:10.1016/j.intcom.2009.07.001 
Amadieu, F., Van Gog, T., Paas, F., Tricot, A., \& Mariné, C. (2009). Effects of prior knowledge and concept-map structure on disorientation, cognitive load, and learning. Learning and Instruction, 19, 376-386. doi:10.1016/j.learninstruc.2009.02.005

Baddeley, A. D. (2003). Working Memory: Looking back and looking forward. Nature Reviews Neuroscience, 4 (10), 829-839. doi: 10.1038/nrn1201.

Britt, M. A., Rouet, J.-F., \&, Perfetti, D. A. (1996). Using hypertext to study and reason about historical evidence. In J.F. Rouet, J. J. Levonen, A. Dillon \& R. J. Spiro (Eds.), Hypertext and cognition (pp. 43-72). Mahwah, NJ: Lawrence Erlbaum.

Calisir, F., \& Gurel, Z. (2003). Influence of text structure and prior knowledge of the learner on reading comprehension, browsing and perceived control. Computers in Human Behavior, 19, 135-145. doi:10.1016/S0747-5632(02)00058-4

Dee-Lucas, D. (1996). Effects of overview structure on study strategies and text representations for instructional hypertext. In J.F. Rouet, J. J. Levonen, A. Dillon \& R. J. Spiro (Eds.), Hypertext and cognition (pp.73-107). Mahwah, NJ: Lawrence Erlbaum.

de Jong, T., \& van der Hulst, A. (2002). The effects of graphical overviews on knowledge acquisition in hypertext: Journal of Computer Assisted Learning, 18, 219-231. doi:10.1046/j.0266-4909.2002.00229.x

Demagistri, M., Richards, M. \& Canet Juric, L. (2014). Incidencia del funcionamiento ejecutivo en el rendimiento en comprensión lectora en adolescentes. Electronic Journal of Re$\begin{array}{lllll}\text { search in } & \text { Educational }\end{array}$ http://dx.doi.org/10.14204/ejrep.33.13146

DeStefano, D. \& Lefevre, J. (2007). Cognitive load in hypertext reading: A review. Computers in Human Behavior, 23, 1616-1641. doi:10.1016/j.chb.2005.08.012

Dillon, A. \& Jobst, J. (2005). Multimedia learning with hypermedia. In: R. Mayer (ed) (2005) The Cambridge Handbook of Multimedia Learning (pp. 569-588). Cambridge MA: Cambridge University Press. doi:10.1017/CBO9780511816819.035

Graesser, A.C. \& Britton, B. (1996). Five metaphors for understanding. In B. K. Britton \& A. C. Graesser (Eds.), Models of understanding text (pp. 341-352). Hillsdale, NJ: Erlbaum.

Graesser, A.C., Leon, J.A., \& Otero, J.C. (2002). Introduction to the psychology of science text comprehension. In J. Otero, J.A. Leon, \& A.C. Graesser (Eds). The psychology of science text comprehension (pp. 1-15). Mahwah, NJ: Erlbaum.

Gwizdka, J. (2009). Cognitive load and web search tasks. In Proceedings of the Third Workshop on Human-Computer Interaction and Information Retrieval (pp.54-57). Washington, DC: Catholic University of America. 
Juvina, I. \& van Oostendorp, H. (2008). Modeling Semantic and Structural Knowledge in Web Navigation. Discourse Processes, 45, 346-364. doi:10.1080/01638530802145205

Klois, S., Segers, E. \& Verhoeven, L. (2013). How hypertext fosters children's knowledge acquisition: The roles of text structure and graphical overview. Computers in Human Behavior, 29, 2047-2057. doi:10.1016/j.chb.2013.03.013

Lee, M. J., \& Tedder, M. C. (2003). The effects of three different computer texts on readers' recall: based on working memory capacity. Computers in Human Behavior, 19, 767-783. doi:10.1016/S0747-5632(03)00008-6

Lusk, D. L., Evans, A. D., Jeffrey, T. R., Palmer, K. R., Wikstrom, C. S., \& Doolittle, P. E. (2009). Multimedia learning and individual differences: Mediating the effects of working memory capacity with segmentation. British Journal of Educational Technology, 40(4), 636-651. doi:10.1111/j.1467-8535.2008.00848.x

Miyake, A. \& Shah, P. (1999). Toward unified theories of working memory: Emerging general consensus, unresolved theoretical issues, and future research directions. In A. Miyake \& P. Shah (Eds.), Models of working memory: Mechanisms of active maintenance and executive control (pp. 442-481). Cambridge, UK: Cambridge University Press. doi:10.1017/CBO9781139174909.016

Müller-Kalthoff, T., \& Möller, J. (2003). The effects of graphical overviews, prior knowledge, and self-concept on hypertext disorientation and learning achievement. Journal of Educational Multimedia and Hypermedia, 12, 117-134.

Müller-Kalthoff, T., \& Möller, J. (2004). The use of graphical overviews in hypertext learning environments. SIGs Instructional Design and Learning, 220-228. Retrieved from http://www.iwm-kmrc.de/workshops/sim2004/pdf_files/Mueller_Kalthoff_et_al.pdf

Naumann, J., Richter, T., Christmann, U., \& Groeben, N. (2008).Working memory capacity and reading skill moderate the effectiveness of strategy training in learning from hypertext. Learning and Individual Differences, 18, 197-213. doi:10.1016/j.lindif.2007.08.007

OECD (2009). PISA 2009 Assessment Framework. Key competencies in reading, mathematics and science. Technical Report. Retrieved from the website http://www.oecd.org/pisa/pisaproducts/44455820.pdf

Paas, F., Renkl, A., \& Sweller, J. (2004). Cognitive load theory: Instructional implications of the interaction between information structures and cognitive architecture. Instructional Science, 32, 1-8. doi:10.1023/B:TRUC.0000021806.17516.d0 
Potelle, H., \& Rouet, J.F. (2003). Effects of content representation and readers' prior knowledge on the comprehension of hypertext. Journal of Human-Computer Studies, 58, $327-345$.

Salmerón, L., Baccino, T., Cañas, J.J., Madrid, R. I., \& Fajardo, I. (2009). Do graphical overviews facilitate or hinder comprehension in hypertext? Computers \& Education, 53, 13081319. doi:10.1016/j.compedu.2009.06.013

Salmerón, L., Cañas, J. J., Kintsch, W. \& Fajardo, I. (2005). Reading strategies and hypertext comprehension. Discourse Processes, 40, 171-191. doi:10.1207/s15326950dp4003_1

Salmerón, L., Kintsch, W., \& Cañas, J.J. (2006). Reading strategies and prior knowledge in learning from hypertext. Memory and Cognition, 34,1157-1171. doi:10.3758/BF03193262

Shapiro, A. M., \& Niederhauser, D. (2004). Learning from hypertext: Research issues and findings. In D. H. Jonassen (Ed.), Handbook of research on educational communications and technology (2nd ed., pp. 605-620). Mahwah, NJ: Lawrence Erlbaum Associates.

Sweller, J. (2004). Instructional design consequences of an analogy between evolution by natural selection and human cognitive architecture. Instructional Science, 12, 185-233. doi:10.1023/B:TRUC.0000021808.72598.4d 
Debora I. Burin et al.

[This page intentionally left blank] 